\title{
Study on Cultivation Technology of High-quality Organic Tea
}

\author{
Haoke Shi \\ Capital Normal University High School, China
}

Keywords: organic tea; current situation; cultivation technology; measures.

\begin{abstract}
Organic tea refers to the tea products and reprocessed products that produce fresh leaf raw materials according to the organic agricultural production system and method in the production area without any pollution source, and are not polluted by any chemicals (synthetic fertilizer, pesticide, growth regulator, etc.) in the process of processing, packaging, storage and transportation, and reviewed and certified by the organic tea certification authority. But it's just tea green. The quality of organic tea stir-fried depends on the climate, altitude, craftsman's skills, and other factors, which are not quantifiable, and the cost is quite high. Organic tea is a kind of pollution-free healthy drink. It adapts to people's increasing health care awareness, has a great potential market, can obtain higher economic benefits, is conducive to tea export, and conforms to the basic national policy of national environmental protection. This paper will mainly focus on the current situation of organic tea planting, point out the planting elements of organic tea, and finally discuss the high-yield cultivation technology of high-quality organic tea.
\end{abstract}

\section{Current situation of organic tea planting}

Organic tea is a kind of green, environmental protection tea, which conforms to the International Federation of Organic Agricultural Movements (IFOAM) standard. It is a kind of tea produced and processed based on the organic agricultural production method, without using any synthetic food additives, pesticides, fertilizers, etc. Organic tea is grown in the most natural state on the land not polluted by pesticides and chemical fertilizers. At the same time, synthetic compounds, chemical fertilizers, and transgenic technology are eliminated during the cultivation period, and no external chemical components are added during the processing of the assembly line. From the processing, production, packaging assembly line production are strictly abide by the specific organic principles. The organic certification of international standards needs to be reviewed annually by a third-party organization from cultivation, processing, production to tea sales.

At present, China has established an organic tea production base of about $400 \mathrm{Hm} 2$, with an annual organic tea production of about 500 tons. In China, green tea is the main organic tea, while a small amount of Oolong tea, black tea, etc. But at present, the amino acid content of green tea in China is generally only $2 \%-7 \%$, the average content of flat tea in Inner Mongolia of Sichuan is $4.8 \%$, the average content of other flat tea is 3.8\%, and the "Emei organic tea" is as high as $24.8 \%$. The content of "catechins" is as high as $11.89 \%$. Tea polyphenols $33.5 \%$, selenium $0.00015 \%$ o, zinc $0.065 \%$ o, iron $0.174 \%$. The kinds and contents of nutrient elements are significantly higher than those of other ordinary tea, and the price of organic tea is 1-2 times of the same kind of ordinary tea. The cultivation of organic tea needs higher quality cultivation techniques.

\section{Construction of high standard ecological tea garden}

\subsection{High standard of land selection}

The tea garden should be located in the area with fresh air and the atmospheric environment quality meeting the first level standard stipulated by the state. The tea field shall be separated from the polluted area and densely populated areas (towns, factories, main lines of traffic), and buffer belts or physical barriers shall be set up if necessary to ensure that the organic tea selection area will not be polluted. 
The soil shall be free from pollution, with high fertility, deep soil layer, loose soil, good permeability, no water accumulation, balanced and rich nutrient elements, and the soil environmental quality shall meet the class I soil environmental quality standard specified by the state. The water of the irrigation river shall be pure, and the water quality shall conform to the class I farmland irrigation water quality standard stipulated by the state. Terraces shall be built to plant tea trees on the slope with a gradient of no more than $25^{\circ}$. The natural vegetation shall not be removed. The biodiversity around the tea garden is relatively rich. Besides, specific plants for water and soil conservation shall be planted. If the ecological environment quality of conventional tea gardens meets the standard of organic tea garden, it can also be transformed into an organic tea garden after 2-3 years of transformation.

\subsection{High standard garden construction}

In the road traffic, the main road and secondary road should be set up, and the road should be connected to a network for the transportation of tea. In terms of drainage system treatment, isolation ditches shall be set horizontally at the junction of tea garden and mountain forest to isolate rainwater runoff, and both ends shall be connected with natural ditches. A longitudinal ditch is arranged along the slope, and the original ditch can be used to remove the redundant surface water in the tea garden. A cross ditch is arranged parallel to the tea row. A cross ditch is opened every 10 to 15 rows in the tea garden on the slope to accumulate rainwater to infiltrate the tea field and discharge the excess rainwater into the longitudinal ditch. The reclamation time of the organic tea garden should be from November to February of the next year. In the treatment of tea gardens with sloping land, it is necessary to measure the high datum line and excavate along the contour line. The topsoil of $20 \mathrm{~cm}$ depth shall be completely returned to the trench; the planting trench shall be excavated according to the standard $(50 \times 80 \mathrm{~cm})$ in depth and width, and the bottom width shall not be less than $60 \mathrm{~cm}$; the horizontal spacing of $1.8 \mathrm{~m}$ is the most appropriate, and the terrace of the slope shall not be less than $1.5 \mathrm{~m}$. When clearing the organic tea forest land, the vegetation at the top and the foot of the mountain should be completely preserved. Remove fir, pine, thatch and other miscellaneous irrigation in the tea garden, and properly retain the broad-leaved trees such as Litsea cubeba. To protect the natural enemies of pests, the isolation zone vegetation should be fully preserved.

The method of organic tea land preparation can be carried out by mechanical land preparation and manual hole drilling. In the application of base fertilizer, the application of base fertilizer is pollution-free, $4-5 \mathrm{~g}$ per hole, and fully mix with the same amount of backfill. After the application of base fertilizer, it should be backfilled with fine topsoil, black soil, humus soil, tree roots, stones, and other impurities as much as possible, and finally, form a bread shaped soil pile $12-15 \mathrm{~cm}$ above the ground.

\section{Key cultivation techniques of organic tea}

\subsection{Methods and means of cultivating improved varieties}

In the selection of good varieties and strong seedlings, it is necessary to select good varieties of tea with strong resistance, adaptability and good quality. The planting time is generally from the end of January to the first ten days of March. At the same time, the planting density should be determined according to different factors in different regions; afforestation should be carried out on rainy days as far as possible, one hole for each tree. When planting, one hand should hold the seedlings, one hand for backfilling, and the seedlings should be planted correctly. The planting depth should be moderate, and the soil should not be too tight when the root-soil contacts. To avoid burning roots, the roots should be about $15 \mathrm{~cm}$ away from the base fertilizer when the base fertilizer is applied. The soil height should be a little higher than the ground.

\subsection{Soil fertilization management}

In the aspect of soil management, the content of heavy metals and soil fertility should be tested regularly every two years, and the improvement measures should be further developed according to 
the data analysis. It can improve the soil structure and fairly prevent soil erosion. Using pollution-free materials to cover the ground can improve the soil's organic content and water storage capacity. To improve (an earthworm, for example) the soil by releasing beneficial microorganisms. Also, scientific fertilization should also be carried out to eliminate weeds manually. Only organic fertilizer, microorganism, mineral, and foliar fertilizer can be used in an organic tea garden. The amount of fertilizer is subject to the type of fertilizer. In addition to the application of fertilizer once a month for new tea seedling planting, fertilizer will be applied two or three times a year, respectively in May, August, and December. Reasonable irrigation (using local common irrigation water source for reasonable and scientific irrigation) and mining instead of cutting. To make tea trees continue to thrive, tea picking should replace traditional tea cutting. It is necessary to ensure the integrity of the fresh leaves of tea by hand, and do not bring the old branches and leaves and tea fruits. No pollution and unleaded gasoline must be used for mechanical tea picking. It is forbidden to use plastic bags and other packages to pack tea leaves. It is necessary to use clean baskets with good ventilation to pack fresh leaves, and the fresh leaves should not be too much, to avoid affecting the quality of fresh leaves.

\subsection{Pest control}

In the process of pest control, common agronomic measures and ecological control are used to coordinate. Agricultural control can be carried out in the following aspects: 1 . Tea is collected in batches for many times, and the development of pests and diseases that threaten the health of buds and leaves such as leafhoppers and mites is eliminated and restrained. 2. Cut off the branches and leaves with pests and take them out of the tea garden for treatment to prevent the spread of pests and diseases. 3. Apply sufficient base fertilizer at the end of autumn, and conduct deep cultivation of tea garden at the same time. 4 . To reduce the pests on the surface of the tea garden, the deciduous leaves and topsoil at the root of the tea tree should be deeply buried. 5. The tea garden should try its best to plant tea varieties that are less affected by local diseases and pests, to reduce the economic losses caused by human or natural conditions in the later stage. Biological control can be carried out in the following aspects: 1. It can be processed into pesticides by pathogenic microorganisms. 2. Protect natural enemies and avoid using pesticides harmful to beneficial insects. 3. When the natural enemies are insufficient, the release of natural enemies can be carried out manually to maintain the balance of the ecosystem, to achieve the goal of pollution-free management.

\section{Conclusion and Prospect}

Since ancient times, tea has played an important role in people's life. Drinking tea is a reflection of people's lifestyle. Through analysis, this paper finds that in today's rapid development of the market economy, the market potential of organic tea is huge.

However, organic tea planting is a new industry, and there is a lack of planting experience. To ensure the quality of organic tea production, especially to reduce the use of pesticides and chemical fertilizers, the application of organic fertilizers should be changed, and biological control should be used to prevent diseases and insect pests. At the same time, it is necessary to recycle the materials of tea trees, promote the measures of returning branches and leaves to the soil, and make the organic tea planting technology more economical and efficient.

The market potential of organic tea is huge, but because it is a new industry, there are still some technical defects. Therefore, practitioners should continue to develop high-end technology, strictly select sites, control the quality of fertilizer, soil, water, air, etc., cultivate tea scientifically, and improve the quality of tea, so that the organic tea market can continue to flourish.

\section{References}

[1] Shuang Youming, Peng Liya, Yang Zhaoliang, et al. Investigation of diseases and insect pests in organic tea garden [J]. Anhui Agricultural Science, 2013 (13): 187-193 
[2] Shen Changwei. Study on pollution-free control technology of main garden plant diseases and insect pests in Zhenhai District, Ningbo [D]. Beijing: Chinese Academy of Agricultural Sciences, 2013

[3] Wang Jian. Exploring soil management and fertilization technology of organic tea standardized cultivation [J]. Friends of farmers, 2018 (16): 189

[4] Wen Bifang. Study on Main Cultivation Techniques of organic tea in Beifeng Youshan, Fuzhou [D]. Fujian Agricultural and Forestry University, 2012

[5] Liu Xin, Fu Songling, Jiang Wenxiu. Effect of intercropping cultivation mode on organic tea quality [J]. Horticulture and seedling, 2015 (07): 1-3

[6] Zhang Ming. Cultivation and management of Nayong mountain ecological organic tea [J]. Modern agriculture, 2018 (07): 5-6 